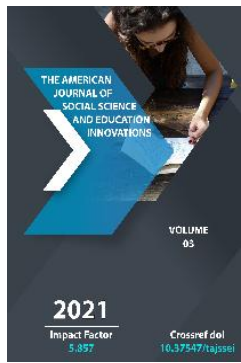

\title{
Student Creativity In Performing Problem-Solving Experiments In Physics Development Through Innovative Technologies
}

Bakhtiyor Berdievich Imanov

PhD, Associate Professor, Termez State University, Termez, Uzbekistan

Journal Website:

http://theamericanjour

nals.com/index.php/taj

ssei

Copyright: Original content from this work may be used under the terms of the creative commons attributes 4.0 licence.

\section{ABSTRACT}

This article discusses the role and importance of innovative technologies in developing students creativity on problematic experiments on physics. It has been shown that innovative technologies help students independently find sources of theoretical knowledge, independently read, analyze data, and even develop their creativity while being able to draw conclusions. The features of innovative technologies and engineering methods are analyzed in the formulation of problematic experiments in physics. The content of the application of each interactive method in carrying out problematic experiments in physics is explained.

\section{KEYWORDS}

Experience, equipment, method, handouts, design, cooperation.

\section{INTRODUCTION}

Innovative technologies teach students to to perform independent tasks, to draw search for sources of theoretical knowledge, analytical 
conclusions from teaching materials. In this process, the teacher plays the role of creating and managing pedagogical conditions for the formation, acquisition and upbringing of the student's personality.

The teacher correctly chooses the necessary laboratory equipment for problem-solving experiments in physics, takes into account the level of knowledge of students, correctly defines the purpose and objectives of the lesson, correctly designs the lesson plan, modern pedagogical, information and communication appropriate use of technology is an important factor in the development of student creativity.

Laboratory classes are one of the forms of lessons aimed at forming, developing thinking and worldview of teachers and students in the implementation of cooperation in the implementation of the experiment. The absence of these indicators in the performance of laboratory classes leads to the emergence in the minds of students of such conditions as boredom, despair and depression. According to the results of pedagogical experiments, it was observed that most students understand the problematic experiment in physics instead of simply performing it. In our opinion, such notions of students are absolutely wrong.

Innovative technologies are implemented in the educational process through the teacher's knowledge, and the student's effective assimilation of innovations in learning. It was studied that the specific features of the use of innovative technologies and interactive methods in performing problem-solving experiments in physics can be:

- Students are not indifferent to problemsolving experiments, focus on independent thinking and creative research;

- Ensuring the continuity of the student's interest in performing the problem experiment;

- Development of teacher-student cooperation in problem-solving.

In designing the performance of a problembased experiment in physics, it would be appropriate for the teacher to be structured taking into account the nature of the physics, the fluency of the student's thinking, and the ability to be flexible.

In lieu of proof of our above opinion, we will focus below on the content of some innovative technologies and interactive methods used in the process of performing a problem experiment in physics: "Networks" ("Cluster") methods. This method serves to expand the scope of logical thinking of students, the formation of skills and competence skills of independent use of educational literature, increase student motivation.

" $3 \times 4$ " methods. This method is aimed at teaching students to think freely and independently, to create solid new ideas, to analyze the problem, to draw conclusions, to describe, to work creatively in small groups.

"Interview" methods. This method is aimed at developing the student's ability to ask questions, listen, answer correctly, formulate the question correctly.

Below we will consider the method of using Boomerang technology in performing a problematic experiment in physics.

Phase I. Students are divided into small groups of 2 people. 
Phase II. The teacher provides each group member with a separate written handout on independent learning, thinking, and performing a new challenging experiment being studied to memorize certain physical quantities. Written handouts consist of a problematic experimental text or table and should be given the same content to all members of the group. This means that a new problem-solving experiment in physics can be divided into at least 10 groups, depending on the number of groups that are already organized. Then each group member will have a separate knowledge of how to perform a new problem experiment from physics.

Phase III. Each member of the group learns and remembers the task of performing a problem experiment in physics individually, and then the group members discuss the content of the problem experiment in a group based on mutual questions and answers. Depending on the size and content of the problem experiment, it will take 5.10 minutes to complete.

Phase IV. The teacher asks the students to take one of the pre-prepared, numbered sheets (the number of sheets should be equal to the number of students in the group. The numbers indicate the group numbers). The teacher suggests forming groups by numbers.

Phase V. Each member of the newly formed group assumes the role of both teacher and student. Each member of the group is required to teach the group the content of the problem experiment he / she performed in the previous group, and in turn the group members master the content of the problem experiment. In doing so, each member of the group should share the content of the problematic experience he or she has performed with others. This will take 8-10 minutes. As a result, new groups formed by numbers are able to master all the materials for performing a problem experiment in a general description.

Phase VI. The group members tell each other the content of performing an independent problem experiment. To check how the completed problem experiment has been mastered, the teacher explains to the group members that they will ask each other questions based on the content of the problem experiment they have performed, and that there is internal control within the group in this way. This helps the group to identify and reinforce to each other how the content of the problematic experience they have performed independently has been assimilated by others.

Phase VII. The teacher asks all students to return to their previous groups. All students return to their original groups.

Phase VIII. The teacher says that given that all students are fully acquainted with the content of the problem-solving materials, they can ask any student in the class questions related to the problem-solving, and the answers to the questions will be evaluated. If the answers to the questions are complete, a grade of " 5 "; if added, a grade of " 4 "; a grade of " 3 " if he / she expresses an opinion while sitting; If the answer is no, a grade of " 2 " is given. A student is assigned to calculate the evaluation of group members 'responses.

Phase IX. The teacher checks the students 'mastery in the groups based on their answers to the test questions in the handouts prepared for the problem-solving experiment.

Phase X. The teacher asks each group member to create 3 test questions based on the problem they have completed and are given 35 minutes. 
Phase XI. At this stage, group members ask each other the test questions they have created. The answers obtained are calculated in the above order. If other group members cannot answer the test questions correctly, the member of that group will complete the answer himself or herself and receive an additional grade.

Phase XII. The final stage is the assessment of the students in the groups on the performance of the problem experiment, the opinions of the students in the group are taken into account in the calculation of the final grades.

Often, there are cases where the correct choice of interactive methods is not sufficiently understood when performing a problematic experiment from Physics. The optimality of this or that method is assessed not by the fact that its name has become commonplace, but by its relevance to the content of the problem experiment to be performed, to the student's ability. Properly selected methods allow to solve the problem in a positive way at the appointed time.

The teacher will be familiar with the instructions for performing a problem experiment to plan a problem experiment in physics, and will define the goals and objectives of the problem.

In performing a problem experiment, the student knows in advance what basic concepts, events, processes, laws, theories, what he can solve, the expected results.

Allocate sufficient time for each problem experiment to plan the content and tasks of that problem experiment, using the interdisciplinary connections provided for in the program;
Selects effective educational technologies and methods in performing problem-solving experiments;

Selects a mutually appropriate combination of forms of organizing the student to perform a problem experiment in general, in small groups and individually;

Makes the necessary adjustments to the forms and methods of performing the problematic experiment, using the option selected during the course.

Student creativity is manifested in the design activity of the process of performing a problem experiment in physics.

It is important to motivate every student who has done a challenging experiment well in physics. Because in some cases, students face some difficulties in performing a problem experiment, and the skill of organizing games and learning discussions in performing a problem experiment is not yet sufficiently formed.

In the performance of a problem experiment, the functions of teaching, educating and developing the lesson process are performed. Using interactive methods in doing this during a challenging experiment will help you to pass the lesson closely. Directing the problem problem performed directly to the student through interaction, using interactive methods, is the basis for performing the problem experiment, in which the teacher does not give ready-made knowledge, but encourages them to search independently.

One of the main requirements for problemsolving is that the methods of problem-solving are closely linked, on this basis to increase the effectiveness of problem-solving, all didactic tasks are solved in the classroom, homework 
is a logical continuation of theoretical knowledge acquired in class. When performing a problem experiment using interactive methods in accordance with these requirements, the teacher should know the following:

The essence of interactive methods;

The role and importance of methods;

Principles of application of interdisciplinary interactive methods;

Business games;

Non-traditional methods;

Forms and ways of organizing, providing creative activity of the student;

Tools and opportunities to improve the student's ability to perform a problematic experience independently.

The use of interactive methods in performing a problem experiment allows the student to acquire practical skills and competencies such as interaction, exchange of ideas, understanding of a specific task, feeling the need to perform it.

\section{REFERENCES}

1. The concept of development of higher education in the Republic of Uzbekistan until 2030.

2. Resolution of the President of the Republic of Uzbekistan No. PK-3775 of 05.06.2018 "On additional measures to improve the quality of education in higher education institutions and ensure their active participation in the ongoing comprehensive reforms in the country."

3. Mahmudov Yu.G. The types of creative activites of pupils when doing laboratory works. European journal of Research and Reflektion in Educational Sciences. Vol. 7 No. 12.2019. ISSN 2056-5852. (-Buyuk Britaniya,2019.12.11.)

4. Mahmudov Yu. G. Laboratory work on determination of electrical conductivity of cotton fiber. European journal of Research and Reflektion in Educational Sciences. Vol. 8 No. 2.2020. ISSN 2056-5852. (-Buyuk Britaniya,02.2020.)

5. Imanov B.B. Lesson and its analysis as factor of increasing the qualiyy of education. European scholar Journal. Available online at// www.scolarzest.com. Vol. № 1 January 2021 ISSN: 2660-5562.

6. B. Imanov. (2020). Specificity Of Student Creative Activity. The American Journal of Social Science and Education Innovations/ 2 (10), 243-249.

7. Shodiev D. Myslitelnyy eksperiment $v$ prepodavanie fizike. $-\mathrm{M}$.: Prosveshchenie, 1987. $-95 \mathrm{p}$.

8. Shodiev D. Myslitelnyy eksperiment $v$ prepodavanie fizike. $-\mathrm{M}$.: Prosveshchenie, 1987. $-95 \mathrm{p}$.

9. Shomirzaev M.X. Problem-based education in the lessons of "Technology" // Modern education. - Tashkent, 2020. Issue 6 (91). - B. 28-35.

10. Shomirzaev M.X. The use of modern teaching methods in teaching schoolchildren folk crafts // Teacher and continuous education. - Nukus, 2020. - 2son. - B. 42-46.

11. Shomirzayev, M. K. (2020). Developing Educational Technologies In School Technology Education. The American Journal of Engineering and Technology, 2(07), 51-57.

12. Shomirzayev, M. K. (2020). The concept of pedagogical technology and basic principles. ACADEMICIA: An International Multidisciplinary Research Journal, 10(11), 1551-1560. 